Review Article

\title{
Chinese Herbs Containing Aristolochic Acid Associated with Renal Failure and Urothelial Carcinoma: A Review from Epidemiologic Observations to Causal Inference
}

\author{
Hsiao-Yu Yang, ${ }^{1,2}$ Pau-Chung Chen, ${ }^{3,4}$ and Jung-Der Wang ${ }^{5,6}$ \\ ${ }^{1}$ Department of Occupational Medicine, Buddhist Tzu Chi General Hospital, No. 707, Section 3, Jhongyang Road, \\ Hualien 97002, Taiwan \\ ${ }^{2}$ School of Medicine, Tzu Chi University, No. 701, Section 3, Jhongyang Road, Hualien 97004, Taiwan \\ ${ }^{3}$ Institute of Occupational Medicine and Industrial Hygiene, National Taiwan University College of Public Health, \\ No. 17 Xuzhou Road, Taipei 100, Taiwan \\ ${ }^{4}$ Department of Environmental and Occupational Medicine, National Taiwan University Hospital and National Taiwan University \\ College of Medicine, No. 1 Jen Ai Road, Section 1, Taipei 100, Taiwan \\ ${ }^{5}$ Department of Public Health, College of Medicine, National Cheng Kung University, No. 1, University Road, Tainan 701, Taiwan \\ ${ }^{6}$ Departments of Internal Medicine and Occupational and Environmental Medicine, National Cheng Kung University Hospital, \\ No. 138, Sheng Li Road, Tainan 704, Taiwan \\ Correspondence should be addressed to Jung-Der Wang; jdwang121@gmail.com
}

Received 29 May 2014; Accepted 8 August 2014; Published 27 August 2014

Academic Editor: Li-Jen Wang

Copyright ( 2014 Hsiao-Yu Yang et al. This is an open access article distributed under the Creative Commons Attribution License, which permits unrestricted use, distribution, and reproduction in any medium, provided the original work is properly cited.

Herbal remedies containing aristolochic acid (AA) have been designated to be a strong carcinogen. This review summarizes major epidemiologic evidence to argue for the causal association between AA exposure and urothelial carcinoma as well as nephropathy. The exposure scenarios include the following: Belgian women taking slimming pills containing single material Guang Fang Ji, consumptions of mixtures of Chinese herbal products in the general population and patients with chronic renal failure in Taiwan, occupational exposure in Chinese herbalists, and food contamination in farming villages in valleys of the Danube River. Such an association is corroborated by detecting specific DNA adducts in the tumor tissue removed from affected patients. Preventive actions of banning such use and education to the healthcare professionals and public are necessary for the safety of herbal remedies.

\section{Introduction}

Epidemiology usually starts from careful clinical observation. In 1993, Vanherweghem et al. first reported an unusual observation that many young Belgian women took slimming pills containing Chinese herb subsequently developing renal failure and upper tract urothelial carcinoma $[1,2]$. The slimming pills contained a Chinese herb "Guang Fang Ji" that has an off-label usage as a diuretic or an immune modulator [3]. At that time, the public generally believed that herbal products are harmless. However, based on the special pathological characteristics of extensive interstitial fibrosis of renal cortex without glomerular lesions, overwhelming upper tract urothelial carcinomas (UTUC), and identification of aristolochic acid (AA) in Chinese herbs [4], Vanherweghem and his colleagues hypothesized that ingestion of the Aristolochia species herbs may be the culprit for the epidemic in Belgium. Subsequently, Chinese herbs associating renal failure and urothelial cancer were reported in many countries [5-8]. Exposure to Aristolochia herbs has raised global public health concerns.

\section{The Epidemiologic Approach}

Because AA is derived from an extract of plants of the Aristolochia, Bragantia, and Asarum species, the further step 
is to determine whether an association between AA and the nephropathy exists in individuals who had similar exposures.

\subsection{Exposures through Prescribed Chinese Herbal Products} in Taiwan. AA is a common ingredient in many Chinese herbs, such as Ma Dou Ling (Aristolochia debilis), Tian Xian Teng (Aristolochia contorta), Qing Mu Xiang (Aristolochia cucurbitifolia), Guang Fang Ji (Aristolochia fangchi), Guan Mu Tong (Aristolochia manshuriensis), and Xixin (Radix et Rhizoma Asari) [9-11], and these herbal remedies are commonly prescribed for many different illnesses, including at least hepatitis, urinary tract infection, vaginitis, oral ulcer, upper respiratory tract infection, eczema, headache, dysmenorrhea, arthralgia, neuralgia, hypertension, cerebrovascular accident, bronchitis, pneumonia, heart failure, and edema [12]. In Taiwan, Chinese herbal remedies are regularly reimbursed through the national healthcare system, which covers more than $97 \%$ of the population [13]. By analyzing the National Health Insurance Reimbursement Database (NHIRD), Hsieh et al. found that herbal drugs containing AA had been prescribed to more than one-third of the population [14]. Besides, patients with a similar pathological finding of AAN in Belgium and history of taking Chinese herbal remedies containing AA were successively reported in Taiwan $[5,6,15$, 16]. As Taiwan was once reported to be the highest incidence of end-stage renal disease (ESRD) worldwide $[17,18]$, AAassociated nephropathy was therefore hypothesized to be one of the major risk factors for developing ESRD in Taiwan. Different from exposure to single Chinese herb in Belgium, Chinese medicine commonly applies mixtures of herbs to enhance efficacy and/or minimize toxicity $[19,20]$. Lai et al. conducted a retrospective follow-up study using a systematic random sample from the NHIRD from 1997 to 2002 and found that the prescription of more than $30 \mathrm{~g}$ of $\mathrm{Mu}$ Tong or more than $60 \mathrm{~g}$ of Guang Fang Ji was associated with an increased risk of chronic kidney disease (CKD) in Taiwan [21]. This study explored the doses of prior exposure to AA containing Chinese herbal remedies and the occurrence of CKD and controlled confounding of use of nonsteroidal antiinflammatory drugs and other risk factors to corroborate the causal hypothesis, indicating that mixtures of herbs did not reduce the nephrotoxicity of $\mathrm{AA}$. In addition, Lai et al. also analyzed the NHIRD in Taiwan and found that people taking AA-containing herbal products had a dosedependent increased risk of urinary tract cancer [22]. There is also an extremely high incidence of UTUC in Taiwan among hemodialysis patients [23], which was corroborated by cases from another hospital with added finding of high recurrence [24]. Although there was no statistical association between taking Chinese herbs and recurrence of cancer [24], it deserves further studies for effective prevention. Wang et al. followed the incidence of urothelial carcinoma among a national representative cohort of 58,739 patients with ESRD in Taiwan during 1997-2002 and reported significantly increased risks for UTUC (SIR $=11.6$; 95\% CI: 10.1-13.1) and bladder cancer (SIR $=13.9 ; 95 \% \mathrm{CI}$ : 12.4-15.0) [25], which is later shown to be associated with the exposure to AA associated Chinese herbal products, especially Guan
Mu Tong) [26]. Wang et al. further followed 90,477 newly diagnosed cases of ESRD in Taiwan between 1997 and 2008 covering the patients aged 40-85. Results showed that female patients had higher risk of UTUC than male after the diagnosis of ESRD; moreover, the cumulative incidence rates and the standardized incidence ratios of UTUC in females appear to decline after the calendar year of 2000 and the time trend is compatible with the decreased consumption of AA after 1998 [27]. In Taiwan, most AA-containing herbs have been prohibited since 2003. If AA is solely the causative agent for the epidemic in Taiwan, we expect that the incidence rate of UTUC in Taiwan will gradually decrease one decade after the cessation of exposure. Common Chinese herbs and formulas containing AA are summarized in Table 1.

\subsection{Occupational Exposures of Chinese Herbalists in Taiwan.} A different exposure setting is through the manufacturing of herbal products by Chinese herbalists. Chinese herbalist is a traditional occupation in Chinese society, and these individuals work in traditional herbal stores [28]. Yang et al. followed the mortality of urological cancers in 6,548 Chinese herbalists in Taiwan between 1985 and 2000, and the results showed that Chinese herbalists had significantly higher risks of mortality due to urological cancers (SMR = 3.10; 95\% CI: 1.41-5.87) and due to chronic and unspecified nephritis, renal failure, and renal sclerosis (SMR $=2.40 ; 95 \%$ CI: 1.40-3.84) [29]. Yang et al. also followed the development of cancer until 2001; the SIRs for kidney and upper urinary tract cancers and bladder cancer were 4.24 (95\% CI 2.476.80) and 2.86 (95\% CI 1.52-4.89), respectively [30]. By assessing the herbalists' exposure at the individual level, Yang et al. found that manufacturing and selling Chinese herbal medicines as well as processing and dispensing herbal medicines containing AA increased the risk of renal failure and UTUC among herbalists due to the ingestion and inhalation of herbal powders at work $[31,32]$. Because herbal particles are visible powders with large molecular weights, the exposure to AA was suspected to occur also via oral route, not only by ingesting herbal remedies containing AA but also by swallowing deposited powder particles in the oropharynx. This viewpoint seems to be supported by the highest risk of UTUC among workers who were exposed to grinding and packing procedures, which usually generates the most significant amount of airborne powders [32].

\subsection{Exposure through Food Contamination in the Balkans.} Balkan endemic nephropathy (BEN) is an environmental disease in farming villages in valleys of the Danube River. BEN and Chinese herbal AAN present similar clinical findings of nephropathy and urothelial carcinoma, which is characterized by slow, progressive renal failure with extensive hypocellular interstitial sclerosis, tubular atrophy, global sclerosis of the glomeruli, and cellular atypia and is also associated with UTUC [33]. These similarities with AAN led to the hypothesis that BEN was associated with dietary exposure to AA-contaminated bread when the seeds of Aristolochia clematitis are harvested along with the wheat used for bread making. In fact, Aristolochia clematitis is a plant that grows 
TABLE 1: A list of Chinese herbs containing aristolochic acids.

\begin{tabular}{|c|c|c|}
\hline Chinese herbal name & Botanical name & Chinese herbal formula containing this herb \\
\hline Guang Fang Ji (Fangchi) & Aristolochia fangchi & $\begin{array}{c}\text { Shu Jing Huo Xue Tang } \\
\text { Shang Zhong Xia Tong Yong Tong Feng } \\
\text { Fang Ji Huang Qi Tang } \\
\text { Xiao Xu Ming Tang } \\
\text { Jie Geng Tang } \\
\text { Mu Fang Ji Tang } \\
\end{array}$ \\
\hline Xixin & Radix et Rhizoma Asari & $\begin{array}{c}\text { Chuan Qiong Cha Diao San } \\
\text { Xiao Qing Long Tang } \\
\text { Du Huo Ji Sheng Tang }\end{array}$ \\
\hline Guan Mu Tong & Aristolochia manshuriensis & $\begin{array}{c}\text { Long Dan Xie Gan Tang } \\
\text { Xin Yi San } \\
\text { Ba Zheng San } \\
\text { Gan Lou Xiao Du Dan } \\
\text { Dao Chi San } \\
\text { Dang Gui Si Ni Tang } \\
\text { Mu Tong } \\
\text { Guo Qi Yin } \\
\text { Xiao Ji Yin Zi } \\
\text { Ju He Wan } \\
\text { Zheng Gu Zi Jin Dan }\end{array}$ \\
\hline Qing Mu Xiang & Aristolochia cucurbitifolia & $\begin{array}{l}\text { Xiang Sha Liu Jun Zi Tang } \\
\text { Gui Pi Tang } \\
\text { Zheng Gu Zi Jin Dan }\end{array}$ \\
\hline Ma Dou Ling & Aristolochia debilis & \\
\hline Tian Xian Teng & Aristolochia contorta & \\
\hline
\end{tabular}

as a weed in endemic areas and contains AA [34], and the etiological evidence of epidemic was also corroborated by Grollman and Jelaković [35].

\subsection{Evidence of DNA Adducts Combined with Epidemiological} Approaches. The suspicion that ingestion of the Aristolochia species herbs may be responsible for the epidemic in Belgium was further corroborated by detection of aristolactam(AL-) DNA adducts formed by metabolites of aristolochic acid (aristolactams) in samples of kidneys removed from five patients with nephropathy [36]. Cosyns et al. subsequently analyzed the urothelial lesions of kidneys and ureters removed during renal transplantation from 10 patients, overexpressed TP53 was observed, which suggested that a TP53 gene mutation plays a role for the carcinogenic effect [37]. Jelaković et al. extracted DNA from the renal cortex and urothelial tumor tissue of 67 patients that underwent nephroureterectomy for carcinomas of the upper urinary tract and resided in regions of Balkan endemic nephropathy. AL-DNA adducts and TP53 mutations were verified in tumor tissues of most patients. In contrast, neither AL-DNA adducts nor specific mutations were detected in tissues of patients residing in nonendemic regions [38]. Wu et al. investigated the chromosomal aberrations of UTUC specimens from seven dialysis patients in Taiwan by conventional comparative genomic hybridization and results showed that gains at $5 p, 7$, and $19 q$ and losses at $4 q, 9 p$, and $15 q$ are common in UTUC of ESRD patients. In addition, female ESRD patients with UTUC had more frequent chromosomal aberrations than their male counterparts [39]. By whole-genome and exome analysis of nine AA-associated UTUCs in Singapore, Poon et al. found a high somatic mutation rate and the AAinduced mutations were also significantly enriched at splice sites, suggesting a role for splice-site mutations in UTUC pathogenesis [40]. Chen et al. analyzed 151 UTUC patients in a medical center of Taiwan and found that AL-DNA adducts were present in the renal cortex of $83 \%$ of patients with $\mathrm{A}: \mathrm{T}$ to T:A mutations in TP53, FGFR3, or HRAS [41]. Results of the molecular epidemiology study were in coherence with the preceded finding in Belgium and therefore provided evidence for the biologic plausibility that the exposure to AA contributes to the development of UTUC.

2.5. Molecular Mechanisms of Renal Damage and Tumor Formation. AA-induced renal damage involves the tubular injury and the interstitium as well [34]. In acute phase, toxicity causes proximal tubule injury [42]. In chronic phase, the apoptosis of the tubular epithelial cells, defective activation of antioxidative enzymes, mitochondrial damage, impaired regeneration of proximal tubular epithelial cells, and interstitial cell proliferation lead to tubular atrophy and interstitial fibrosis [34, 43-45]. Because human urothelial tissue is rich in peroxidases, the aristolactams activated by peroxidase may result in the formation of the AL-DNA adducts in urothelial tissue $[46,47]$ and lead to A : T to T: A transverse mutations in the TP53 tumor suppression gene 
$[38,41,47,48]$, as demonstrated by overexpression of TP53 protein in patients with AAN and urothelial carcinoma [37]. Since the TP53 can promote cell-cycle checkpoints, DNA repair, and apoptosis [49], its mutation may play an important role for the AA-induced carcinogenic effect in human studies $[37,38,41]$. In rat model, AL-DNA adducts were also detected in the renal cortex of AA-treated rats [42]. In vitro studies, AA can induce AL-DNA adducts in proximal tubular cell line [50].

2.6. From Epidemiologic Observations to Causal Inference. AA-induced kidney disease was once referred to as Chinese herbs nephropathy because of frequent occurrence in people taking Chinese herbal remedies, but it is now more accurately termed as aristolochic acid nephropathy (AAN) because the nephropathy is also observed in food contamination [51], occupational exposure [29, 30, 32], and so forth. Exposure to AA causes not only UTUC but also bladder cancer [52]. In determining whether an association is causal, the Hill criteria of causation are often applied [53, 54]. Clear temporal relationship between AA exposure and subsequently developed nephropathy and urological caner are observed in all epidemiological studies in Belgium and Taiwan. The association cannot be explained by alternative factors, including arsenic, cigarette smoking, and NSAID after appropriate control of confounding in these studies [22]. Moreover, a dose-response relationship was documented for AA exposure and UTUC based on the national-wide Chinese herbal pharmacoepidemiological studies in Taiwan, in which a threshold of herbal doses is also provided [22]. In different exposed populations in Belgium, Taiwan, and Balkan Peninsula, there are consistent and replicable findings that the AA exposures associate with increased risks for the occurrence of nephropathy and urothelial carcinoma. Moreover, a biologically plausible mechanism has been demonstrated by detection of gene mutations and DNA adducts, which appear to be specific in pathological finding and corroborates such a causal relationship (Figure 1). Thus, it is not a surprise that herbal remedies containing plant species of the genus Aristolochia have been designated to be a Group 1 carcinogen in humans [55].

\section{Diagnosis of AA-Induced Nephropathy and Urothelial Carcinoma}

3.1. Clinical Characteristics. AAN is characterized by anemia, mild tubular proteinuria, and initially normal blood pressure in approximately one-half of patients. Differences in disease progression may relate to the total dose of AA that was ingested [6]. Human subjects with high AA intake may progress to renal failure after 1 to 7 years, although subjects with a low cumulative AA intake can often maintain relatively normal kidney function over the course of 2-8 years of follow-up [56]. Based on a study including 39 patients with AAN who underwent prophylactic surgery, a cumulative dose of more than $200 \mathrm{~g}$ of Guang Fang Ji was associated with a higher risk of urothelial carcinoma [2]. Most of the cases of urothelial carcinoma were detected in AAN patients with ESRD. However, AA-induced urothelial carcinoma may occur without severe renal failure [57]. In contrast to the usual concept that urothelial carcinoma is more likely to develop in males than females $[58,59]$, the female gender has been shown to be associated with a higher risk of developing AArelated urothelial carcinoma $[29,60,61]$.

3.2. Laboratory Findings. In $\mathrm{AAN}$, microalbuminuria and the urinary excretion of beta 2-microglobulin appear to represent an early marker of tubular damage [62]. In such cases, there are also elevated levels of urine retinol-binding protein, urine $\mathrm{N}$-acetyl-beta-glucosaminidase, anemia, and glucosuria [63].

3.3. Pathological Findings. Proximal renal tubular dysfunction and structural destruction would be the main positive findings in renal biopsy [63]. AAN has been classified as a separate entity of progressive tubulointerstitial nephropathy. The major pathological findings of AAN include hypocellular interstitial fibrosis, tubular atrophy, tubular brush border ablation, fibromyxoid or fibrous intimal thickening mainly of the interlobular arteries, mild to severe hyalinization, and sclerosis of the glomeruli decreasing from the outer to the inner cortex [63-67]. Urothelial malignancy is observed mainly in the upper urinary tract, such as the ureter and pelvis, during the first three years after exposure [37] but can also be observed in the bladder, with an approximately equal tendency, after longer follow-up periods [52]. The carcinogenesis of AA is associated with specific A : T to T:A mutations in the TP53 tumor-suppressor gene [37, 68-70].

3.4. AA Detection Method. To verify the exposure to AA, ultra-high-performance liquid chromatography-multistage fragmentation mass spectrometry can be applied to determine the presence of aristolochic acid I (AA I) and aristolochic acid II (AA II) in herbal dietary supplements [71]. Yang et al. reported a hollow fiber liquid-phase microextraction technique in conjunction with high-performance liquid chromatography for the extraction and quantitation of aristolochic acid I in human urine samples [72]. Following metabolic activation, AAs can form AL-DNA adducts in the renal cortex or ureteral tissues, which can serve as biomarkers of exposure to AA $[2,36,38,48,73]$. In addition, the ${ }^{32} \mathrm{P}$ postlabelling method can be used to detect AL-DNA adducts [74], although new liquid chromatography-mass spectrometry (LC-MS) methods have been applied in human renal cortex tissues $[73,75]$. A noninvasive and efficient method using ultraperformance liquid chromatography-triple quadrupole mass spectrometry has also been developed to detect ALDNA adducts in exfoliated urothelial cells $[73,76]$.

3.5. Treatment and Follow-Up. Steroid therapy was shown to slow the progression of renal failure in AAN $[77,78]$. Regular medical follow-up is necessary for Chinese herbalists and those who have taken AA-containing herbal remedies. Because the prevalence of urothelial carcinoma among patients with end-stage AAN is high [2], prophylactic surgery to remove the ureter and kidney has been performed in patients with end-stage AAN in Belgium [37]. Because 


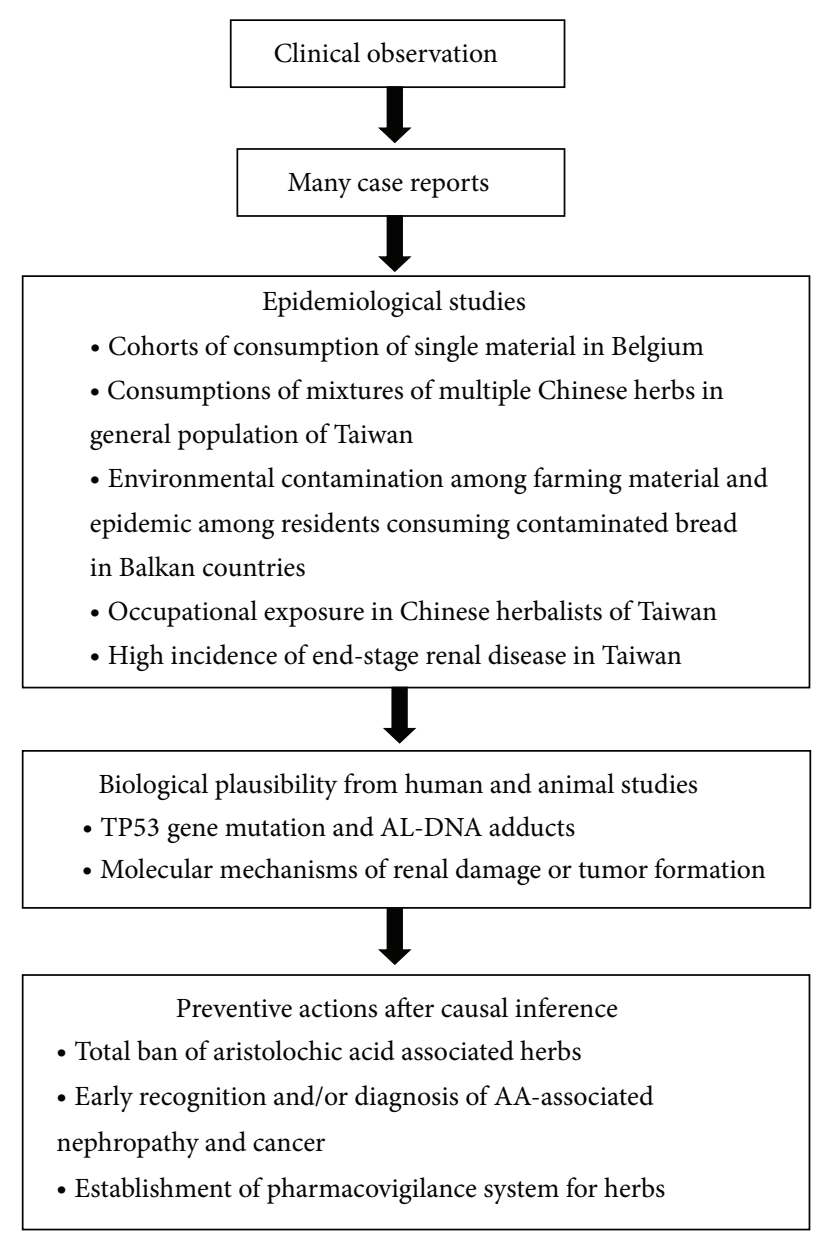

FIGURE 1: The sequence of establishing causality.

the exposure to AA increases the risk for bladder cancer $[22,27,52]$, yearly screening by cystoscopy and computed tomography is recommended in patients with AAN $[79,80]$.

\section{From Observational Studies to Preventive Actions}

There has been an increase in the use of Chinese herbal remedies in Taiwan [14] and possibly worldwide [81]. Thus, AA epidemics have a significant implication for the safety of herbal remedies. Moreover, the misuse or substitution of Chinese herbs is common due to the inconsistent nomenclature system and the similarity of the names and appearance of many herbs [82]. For example, Han Fang Ji is often replaced by Guang Fang Ji, Mu Tong by Guan Mu Tong, and Mu Xiang by Qing $\mathrm{Mu}$ Xiang [82-85]. Although Chinese medicine is regarded as a formal medical treatment in the health care system of Taiwan [86] and Chinese herbal remedies are manufactured in certificated pharmaceutical factories, adulteration remains common due to the loose regulations and enforcement requiring factories to validate relatively few items. To proactively prevent the adverse reactions caused by Chinese herbal remedies and protect the public, Chinese herbal remedies and online herbal products must be regularly monitored by the Food and Drug Administration (FDA) to ensure that products are evaluated for their safety before marketing. Proper labeling and good surveillance systems will further protect consumers. Moreover, incorporating Chinese herbal drugs into the adverse drug reaction or poison surveillance system may be another effective way to achieve this goal [87]. In clinical practice, we recommend that physicians always keep in mind the possible consumption of herbs when treating a patient with renal disease or urological cancer. Although the US FDA bans all botanical remedies known or suspected to contain AA, AA I and AA II were detected in $20 \%$ and $7 \%$, respectively, of tested samples in a survey of thirty herbal products marketed in the US via the Internet [71]. Xixin, which contains minute amount of AA $[10,88,89]$, is still widely used in Asia, including Japan, Korea, China, and Taiwan, because Chinese medicine practitioners claim that its toxicity is negligible. However, AAN associated with Xixin was reported [15]. We suggest that the governments must adopt more restrictive regulations to eliminate all AA-containing herbs to protect public health.

In Chinese medicine, toxic herbs are seldom prescribed or used alone; in fact, traditional Chinese remedies are usually prescribed as complex mixtures of several different medicinal plants based on the ancient principle of "sovereign, minister, 
assistant, and courier," which assigns each ingredient in a prescribed Chinese herbal formula a unique role so that the combination of them can enhance the main effect and reduce the toxicity of herbs $[18,19]$. For example, minerals are commonly used in Chinese herbals remedies, and Chinese herbalists believe that the toxicity of minerals can be removed by traditional processing operations, including heating and quenching in vinegar, referred to as "pao zhi" [90]. However, no scientific evidence has shown that toxic contents, such as AA or heavy metals, can be eliminated by these methods. As the Chinese herbal products containing AA have been consistently shown to be associated with urothelial carcinoma, we must inform the general public, Chinese medicine practitioners, and healthcare professionals of proactively taking necessary precautions to avoid exposure to AA associated Chinese herbal products, establishing a pharmacovigilance system for traditional herbs, and continuing monitoring those who were exposed before. Because Taiwanese people may obtain herbs and herbal medicines from many different sources $[3,91]$, physicians shall still keep on watching potential nephrotoxicity of medicines even after AA-associated herbs were mostly removed from Chinese herbal products prescribed under the National Health Insurance system.

\section{Acknowledgment}

This research was, in part, supported by the Ministry of Education, Taiwan, The Aim for the Top University Project to the National Cheng Kung University (NCKU).

\section{Conflict of Interests}

The authors declare that there is no conflict of interests regarding the publication of this paper.

\section{References}

[1] J.-L. Vanherweghem, M. Depierreux, C. Tielemans et al., "Rapidly progressive interstitial renal fibrosis in young women: association with slimming regimen including Chinese herbs," The Lancet, vol. 341, no. 8842, pp. 387-391, 1993.

[2] J. L. Nortier, M. M. Martinez, H. H. Schmeiser et al., "Urothelial carcinoma associated with the use of a Chinese herb (Aristolochia fangchi)," The New England Journal of Medicine, vol. 342, no. 23, pp. 1686-1692, 2000.

[3] C. H. Lin and C. S. Yang, "Chinese herbs nephropathy," Journal of Internal Medicine of Taiwan, vol. 13, no. 6, pp. 276-281, 2002 (Chinese).

[4] M. Vanhaelen, R. Vanhaelen-Fastre, P. But, and J. Vanherweghem, "Identification of aristolochic acid in Chinese herbs," The Lancet, vol. 343, article 174, 1994.

[5] C. S. Yang, C. H. Lin, S. H. Chang, and H. C. Hsu, "Rapidly progressive fibrosing interstitial nephritis associated with Chinese herbal drugs," American Journal of Kidney Diseases, vol. 35, no. 2, pp. 313-318, 2000.

[6] C. Chang, Y. Wang, A. Yang, and S. Chiang, "Rapidly progressive interstitial renal fibrosis associated with Chinese herbal medications," American Journal of Nephrology, vol. 21, no. 6, pp. 441-448, 2001.
[7] X. B. Li, N. Z. Xing, Y. Wang, X. Hu, H. Yin, and X. Zhang, "Transitional cell carcinoma in renal transplant recipients: a single center experience," International Journal of Urology, vol. 15, no. 1, pp. 53-57, 2008.

[8] G. M. Lord, T. Cook, V. M. Arlt, H. H. Schmeiser, G. Williams, and C. D. Pusey, "Urothelial malignant disease and Chinese herbal nephropathy," The Lancet, vol. 358, no. 9292, pp. 15151516, 2001.

[9] C. Zhang, X. Wang, M. Shang et al., "Simultaneous determination of five aristolochic acids and two aristololactams in Aristolochia plants by high-performance liquid chromatography," Biomedical Chromatography, vol. 20, no. 4, pp. 309-318, 2006.

[10] T. T. Jong, M. R. Lee, S. S. Hsiao et al., "Analysis of aristolochic acid in nine sources of Xixin, a traditional Chinese medicine, by liquid chromatography/atmospheric pressure chemical ionization/tandem mass spectrometry," Journal of Pharmaceutical and Biomedical Analysis, vol. 33, no. 4, pp. 831-837, 2003.

[11] A. K. Drew, I. M. Whyte, A. Bensoussan, A. H. Dawson, X. Zhu, and S. P. Myers, "Chinese herbal medicine toxicology database: monograph on herba asari, 'xi xin", Journal of Toxicology, vol. 40, no. 2, pp. 169-172, 2002.

[12] M. N. Lai, J. N. Lai, P. C. Chen, S. H. Hsieh, F. C. Hu, and J. D. Wang, "Risks of kidney failure associated with consumption of herbal products containing Mu Tong or Fangchi: a populationbased case-control study," American Journal of Kidney Diseases, vol. 55, no. 3, pp. 507-518, 2010.

[13] J. R. Lu and W. C. Hsiao, "Does universal health insurance make health care unaffordable? Lessons from Taiwan," Health Affairs, vol. 22, no. 3, pp. 77-88, 2003.

[14] S. C. Hsieh, I. H. Lin, W. L. Tseng, C. H. Lee, and J. D. Wang, "Prescription profile of potentially aristolochic acid containing Chinese herbal products: an analysis of National Health Insurance data in Taiwan between 1997 and 2003," Chinese Medicine, vol. 3, article no. 13, 2008.

[15] H. Y. Yang, J. L. Lin, K. H. Chen, C. C. Yu, P. Y. Hsu, and C. L. Lin, "Aristolochic acid-related nephropathy associated with the popular Chinese herb Xi Xin," Journal of Nephrology, vol. 19, no. 1, pp. 111-114, 2006.

[16] Y. T. Hong, L. S. Fu, L. H. Chung, S. C. Hung, Y. T. Huang, and C. S. Chi, "Fanconi's syndrome, interstitial fibrosis and renal failure by aristolochic acid in Chinese herbs," Pediatric Nephrology, vol. 21, no. 4, pp. 577-579, 2006.

[17] National Institute of Diabetes and Digestive and Kidney Diseases, "U.S. Renal Data System, USRDS Annual Data Report: International Comparisons," 2006, http://www.usrds.org/.

[18] A. J. Collins, B. Kasiske, C. Herzog et al., "Excerpts from the United States renal data system 2004 annual data report: atlas of end-stage renal disease in the United States," American Journal of Kidney Diseases, vol. 45, no. 1, supplement 1, pp. S1-S280, 2005.

[19] H.-D. Neijing, The Yellow Emperor's Classic of Medicine, Western Han Dynasty, 1995, (Chinese).

[20] J. T. Cheng, "Review: drug therapy in Chinese traditional medicine," Journal of Clinical Pharmacology, vol. 40, no. 5, pp. 445-450, 2000.

[21] M. N. Lai, J. N. Lai, P. C. Chen et al., "Increased risks of chronic kidney disease associated with prescribed Chinese herbal products suspected to contain aristolochic acid," Nephrology, vol. 14, no. 2, pp. 227-234, 2009.

[22] M. N. Lai, S. M. Wang, P. C. Chen, Y. Chen, and J. Wang, "Population-based case-control study of chinese herbal products containing aristolochic acid and urinary tract cancer risk," 
Journal of the National Cancer Institute, vol. 102, no. 3, pp. 179186,2010

[23] C.-H. Chang, C.-M. Yang, and A.-H. Yang, "Renal diagnosis of chronic hemodialysis patients with urinary tract transitional cell carcinoma in Taiwan," Cancer, vol. 109, no. 8, pp. 1487-1492, 2007.

[24] T. Y. Wang, C. J. Hu, C. W. Kuo et al., "High incidence and recurrence of transitional cell carcinoma in Taiwanese patients with end-stage renal disease," Nephrology, vol. 16, no. 2, pp. 225231, 2011.

[25] S. M. Wang, M. N. Lai, P. C. Chen et al., "Increased risk of urothelial cancer in young and middle aged patients with end-stage renal disease," Journal of the Formosan Medical Association, 2013.

[26] S. M. Wang, M. N. Lai, A. Wei et al., "Increased risk of urothelial cancer in young and middle aged patients with end-stage renal disease," PloS ONE, 2013.

[27] S. M. Wang, M. N. Lai, and P. C. Chen, "Increased upper and lower tract urothelial carcinoma in patients with end stage renal disease: a nationalwide cohort study in Taiwan during 1997-2008," BioMed Research International, vol. 2014, Article ID 149750, 9 pages, 2014.

[28] C. Chi, J. L. Lee, J. S. Lai, C. Y. Chen, S. K. Chang, and S. C. Chen, "The practice of Chinese medicine in Taiwan," Social Science and Medicine, vol. 43, no. 9, pp. 1329-1348, 1996.

[29] H. Y. Yang, J. D. Wang, T. C. Lo, and P. C. Chen, "Increased Mortality risk for cancers of the kidney and other urinary organs among Chinese herbalists," Journal of Epidemiology, vol. 19, no. 1, pp. 17-23, 2009.

[30] H. Y. Yang, J. D. Wang, T. C. Lo, and P. C. Chen, "Increased risks of upper tract urothelial carcinoma in male and female Chinese herbalists," Journal of the Formosan Medical Association, vol. 110, no. 3, pp. 161-168, 2011.

[31] H. Y. Yang, J. D. Wang, T. C. Lo, and P. C. Chen, “Occupational kidney disease among Chinese herbalists exposed to herbs containing aristolochic acids," Occupational and Environmental Medicine, vol. 68, no. 4, pp. 286-290, 2011.

[32] H. Y. Yang, J. D. Wang, T. C. Lo, and P. C. Chen, "Occupational exposure to herbs containing aristolochic acids increases the risk of urothelial carcinoma in Chinese herbalists," Journal of Urology, vol. 189, no. 1, pp. 48-52, 2013.

[33] I. N. Chernozemsky, I. S. Stoyanov, T. K. Petkova-Bocharova et al., "Geographic correlation between the occurrence of endemic nephropathy and urinary tract tumours in Vratza district, Bulgaria," International Journal of Cancer, vol. 19, no. 1, pp. 111, 1977.

[34] F. D. Debelle, J. Vanherweghem, and J. L. Nortier, "Aristolochic acid nephropathy: a worldwide problem," Kidney International, vol. 74, no. 2, pp. 158-169, 2008.

[35] A. P. Grollman and B. Jelaković, "Role of environmental toxins in endemic (Balkan) nephropathy," Journal of the American Society of Nephrology, vol. 18, no. 11, pp. 2817-2823, 2007.

[36] H. H. Schmeiser, C. A. Bieler, M. Wiessler, C. Van Ypersele De Strihou, and J. Cosyns, "Detection of DNA adducts formed by aristolochic acid in renal tissue from patients with Chinese herbs nephropathy," Cancer Research, vol. 56, no. 9, pp. 20252028, 1996.

[37] J. P. Cosyns, M. Jadoul, J. P. Squifflet, F. Wese, and C. V. Y. De Strihou, "Urothelial lesions in Chinese-herb nephropathy," American Journal of Kidney Diseases, vol. 33, no. 6, pp. 1011-1017, 1999.
[38] B. Jelaković, S. Karanović, I. Vuković-Lela et al., "AristolactamDNA adducts are a biomarker of environmental exposure to aristolochic acid," Kidney International, vol. 81, no. 6, pp. 559$567,2012$.

[39] C. F. Wu, S. T. Pang, J. J. Shee et al., "Identification of genetic alterations in upper urinary tract urothelial carcinoma in endstage renal disease patients," Genes Chromosomes and Cancer, vol. 49, no. 10, pp. 928-934, 2010.

[40] S. L. Poon, S. T. Pang, J. R. McPherson et al., "Genome-wide mutational signatures of aristolochic acid and its application as a screening tool," Science Translational Medicine, vol. 5, Article ID 197ra01, 2013.

[41] C. H. Chen, K. G. Dickman, M. Moriya et al., "Aristolochic acid-associated urothelial cancer in Taiwan," Proceedings of the National Academy of Sciences of the United States of America, vol. 109, no. 21, pp. 8241-8246, 2012.

[42] C. Lebeau, F. D. Debelle, V. M. Arlt et al., "Early proximal tubule injury in experimental aristolochic acid nephropathy: functional and histological studies," Nephrology Dialysis Transplantation, vol. 20, no. 11, pp. 2321-2332, 2005.

[43] A. A. Pozdzik, I. J. Salmon, F. D. Debelle et al., "Aristolochic acid induces proximal tubule apoptosis and epithelial to mesenchymal transformation," Kidney International, vol. 73, no. 5, pp. 595-607, 2008.

[44] F. D. Debelle, J. L. Nortier, E. G. de Prez et al., "Aristolochic acids induce chronic renal failure with interstitial fibrosis in saltdepleted rats," Journal of the American Society of Nephrology, vol. 13, no. 2, pp. 431-436, 2002.

[45] L. Yang, X. Li, and H. Wang, "Possible mechanisms explaining the tendency towards interstitial fibrosis in aristolochic acidinduced acute tubular necrosis," Nephrology Dialysis Transplantation, vol. 22, no. 2, pp. 445-456, 2007.

[46] M. Stiborová, E. Frei, A. Breuer, C. A. Bieler, and H. H. Schmeiser, "Aristolactam I a metabolite of aristolochic acid I upon activation forms an adduct found in DNA of patients with chinese herbs nephropathy," Experimental and Toxicologic Pathology, vol. 51, no. 4-5, pp. 421-427, 1999.

[47] V. M. Arlt, M. Stiborova, and H. H. Schmeiser, "Aristolochic acid as a probable human cancer hazard in herbal remedies: a review," Mutagenesis, vol. 17, no. 4, pp. 265-277, 2002.

[48] C. H. Chen, K. G. Dickman, M. Moriya et al., "Aristolochic acid-associated urothelial cancer in Taiwan," Proceedings of the National Academy of Sciences of the United States of America, vol. 109, no. 21, pp. 8241-8246, 2012.

[49] J. S. Fridman and S. W. Lowe, "Control of apoptosis by p53," Oncogene, vol. 22, no. 56, pp. 9030-9040, 2003.

[50] C. Lebeau, V. M. Arlt, H. H. Schmeiser et al., "Aristolochic acid impedes endocytosis and induces DNA adducts in proximal tubule cells," Kidney International, vol. 60, no. 4, pp. 1332-1342, 2001.

[51] G. Gillerot, M. Jadoul, V. M. Arlt et al., "Aristolochic acid nephropathy in a Chinese patient: time to abandon the term "Chinese herbs nephropathy"?" American Journal of Kidney Diseases, vol. 38, no. 5, p. E26, 2001.

[52] A. Lemy, K. M. Wissing, S. Rorive et al., "Late onset of bladder urothelial carcinoma after kidney transplantation for end-stage aristolochic acid nephropathy: a case series with 15-year followup," American Journal of Kidney Diseases, vol. 51, no. 3, pp. 471477, 2008.

[53] A. B. Hill, "The environment and disease: association or causation?" Proceedings of the Royal Society of Medicine, vol. 58, pp. 295-300, 1965. 
[54] K. J. Rothman and S. Greenland, "Causation and causal inference in epidemiology," The American Journal of Public Health, vol. 95, no. 1, pp. S144-S150, 2005.

[55] International Agency for Research on Cancer, Some Traditional Herbal Medicines, Some Mycotoxins, Naphthalene and Styrene, vol. 82 of IARC Monographs on the Evaluation of Carcinogenic Risks to Humans, 2002, http://monographs.iarc .fr/ENG/Monographs/vol82/index.php.

[56] L. Yang, T. Su, X. M. Li et al., "Aristolochic acid nephropathy: variation in presentation and prognosis," Nephrology Dialysis Transplantation, vol. 27, no. 1, pp. 292-298, 2012.

[57] J. L. Nortier, H. H. Schmeiser, M.-. Muniz Martinez et al., "Invasive urothelial carcinoma after exposure to Chinese herbal medicine containing aristolochic acid may occur without severe renal failure," Nephrology Dialysis Transplantation, vol. 18, no. 2, pp. 426-428, 2003.

[58] G. D. Stewart, S. V. Bariol, K. M. Grigor, D. A. Tolley, and S. A. McNeill, "A comparison of the pathology of transitional cell carcinoma of the bladder and upper urinary tract," BJU International, vol. 95, no. 6, pp. 791-793, 2005.

[59] S. L. Johansson and S. M. Cohen, "Epidemiology and etiology of bladder cancer," Seminars in Surgical Oncology, vol. 13, pp. 291-298, 1997.

[60] M. Djokic, J. Hadzi-Djokic, J. Nikolic, D. Dragicevic, and D. Radivojevic, "Comparison of upper urinary tract tumours in the region of Balkan endemic nephropathy with urothelial tumours observed in other regions," Progres en Urologie, vol. 9, no. 1, pp. 61-68, 1999.

[61] M. Miletić-Medved, A. M. Domijan, and M. Peraica, "Recent data on endemic nephropathy and related urothelial tumors in Croatia," Wiener Klinische Wochenschrift, vol. 117, no. 17, pp. 604-609, 2005.

[62] V. Stefanović, L. Djukanović, R. Čukuranović et al., "Beta2microglobulin and alphal-microglobulin as markers of Balkan endemic nephropathy, a worldwide disease," Renal Failure, vol. 33, no. 2, Article ID 552152, pp. 176-183, 2011.

[63] D. Chen, Z. Tang, C. Luo, H. Chen, and Z. Liu, "Clinical and pathological spectrums of aristolochic acid nephropathy," Clinical Nephrology, vol. 78, no. 1, pp. 54-60, 2012.

[64] J. L. Nortier and J. L. Vanherweghem, "Renal interstitial fibrosis and urothelial carcinoma associated with the use of a Chinese herb (Aristolochia fangchi)," Toxicology, vol. 181-182, pp. 577$580,2002$.

[65] J. P. Cosyns, "Aristolochic acid and "Chinese herbs nephropathy": a review of the evidence to date," Drug Safety, vol. 26, no. 1, pp. 33-48, 2003.

[66] J. P. Cosyns, M. Jadoul, J. Squifflet, J. De Plaen, D. Ferluga, and C. Van Ypersele De Strihou, "Chinese herbs nephropathy: a clue to Balkan endemic nephropathy?" Kidney International, vol. 45, no. 6, pp. 1680-1688, 1994.

[67] J. P. Cosyns, J. P. Dehoux, Y. Guiot et al., "Chronic aristolochic acid toxicity in rabbits: a model of Chinese herbs nephropathy?" Kidney International, vol. 59, no. 6, pp. 2164-2173, 2001.

[68] M. Moriya, N. Slade, B. Brdar et al., "TP53 Mutational signature for aristolochic acid: an environmental carcinogen," International Journal of Cancer, vol. 129, no. 6, pp. 1532-1536, 2011.

[69] G. M. Lord, M. Hollstein, V. M. Arlt et al., "DNA adducts and p53 mutations in a patient with aristolochic acid-associated nephropathy," American Journal of Kidney Diseases, vol. 43, no. 4, pp. el1-e17, 2004.
[70] A. J. Schetter and C. C. Harris, "Tumor suppressor p53 (TP53) at the crossroads of the exposome and the cancer genome," Proceedings of the National Academy of Sciences of the United States of America, vol. 109, no. 21, pp. 7955-7956, 2012.

[71] L. Vaclavik, A. J. Krynitsky, and J. I. Rader, "Quantification of aristolochic acids I and II in herbal dietary supplements by ultra-high-performance liquid chromatography-multistage fragmentation mass spectrometry," Food Additives \& Contaminants A, Chemistry, Analysis, Control, Exposure Risk Assessment, vol. 31, no. 5, pp. 784-791, 2014.

[72] Y. Yang, J. Chen, and Y. P. Shi, "Determination of aristolochic acid in urine using hollow fiber liquid-phase microextraction combined with high-performance liquid chromatography," Biomedical Chromatography, vol. 24, no. 12, pp. 1350-1355, 2010.

[73] Z. W. Cai, A. Y. Chan, and Z. Z. Zhao, "Rapid and specific determination of DNA adducts for clinical diagnosis of poisoning and disease associated with aristolochic acid," Hong Kong Academy of Medicine, vol. 19, supplement 9, pp. 40-43, 2013.

[74] C. A. Bieler, M. Stiborova, M. Wiessler, J. Cosyns, C. Van Ypersele De Strihou, and H. H. Schmeiser, "32P-post-labelling analysis of DNA adducts formed by aristolochic acid in tissues from patients with Chinese herbs nephropathy," Carcinogenesis, vol. 18, no. 5, pp. 1063-1067, 1997.

[75] B. H. Yun, T. A. Rosenquist, V. Sidorenko et al., "Biomonitoring of aristolactam-DNA adducts in human tissues using ultraperformance liquid chromatography/ion-trap mass spectrometry," Chemical Research in Toxicology, vol. 25, no. 5, pp. 1119-1131, 2012.

[76] L. Guo, H. Wu, H. Yue, S. Lin, Y. Lai, and Z. Cai, "A novel and specific method for the determination of aristolochic acidderived DNA adducts in exfoliated urothelial cells by using ultra performance liquid chromatography-triple quadrupole mass spectrometry," Journal of Chromatography B, vol. 879, no. 2, pp. 153-158, 2011.

[77] J. L. V. Vanherweghem, D. Abramowicz, C. Tielemans, and M. Depierreux, "Effects of steroids on the progression of renal failure in chronic interstitial renal fibrosis: a pilot study in Chinese herbs nephropathy," The American Journal of Kidney Diseases, vol. 27, no. 2, pp. 209-215, 1996.

[78] W. Chen, Y. Chen, and A. Li, “The clinical and pathological manifestations of aristolochic acid nephropathy-the report of 58 cases," Zhonghua Yi Xue Za Zhi, vol. 81, no. 18, pp. 1101-1105, 2001.

[79] A. R. Zlotta, T. Roumeguere, C. Kuk et al., "Select screening in a specific high-risk population of patients suggests a stage migration toward detection of non-muscle-invasive bladder cancer," European Urology, vol. 59, no. 6, pp. 1026-1031, 2011.

[80] M. Refik Gökmen, J. Cosyns, V. M. Arlt et al., "The epidemiology, diagnosis, and management of aristolochic acid nephropathy: a narrative review," Annals of Internal Medicine, vol. 158, no. 6, pp. 469-477, 2013.

[81] S. Wachtel-Galor and I. F. F. Benzie, "Herbal medicine: an introduction to its history, usage, regulation, current trends, and research needs," in Herbal Medicine: Biomolecular and Clinical Aspects, I. F. F. Benzie and S. Wachtel-Galor, Eds., CRC Press, Boca Raton, Fla, USA, 2nd edition, 2011.

[82] K. M. Wu, J. G. Farrelly, R. Upton, and J. Chen, "Complexities of the herbal nomenclature system in traditional Chinese medicine (TCM): lessons learned from the misuse of Aristolochia-related species and the importance of the pharmaceutical name during botanical drug product development," Phytomedicine, vol. 14, no. 4, pp. 273-279, 2007. 
[83] M. S. Chuang, Y. H. Hsu, C. C. Chang et al., "Studies on adulteration and misusage of Asari radi in the market," Annual Scientific Report of National Laboratories of Foods and Drugs, Taiwan R.O.C., vol. 21, pp. 153-167, 2003 (Chinese).

[84] C. F. Tung, Y. L. Ho, H. Y. Tsai et al., "Studies on the commonly misused and adulterated Chinese crude drug species in Taiwan," China Medical College Journal, vol. 8, pp. 35-46, 1999 (Chinese).

[85] T. P. Cheung, C. Xue, K. Leung, K. Chan, and C. Li, "Aristolochic acids detected in some raw Chinese medicinal herbs and manufactured herbal products-a consequence of inappropriate nomenclature and imprecise labelling?" Clinical Toxicology, vol. 44, no. 4, pp. 371-378, 2006.

[86] C. T. Liu, "Health care systems in transition II. Taiwan, Part I. A general overview of the health care system in Taiwan," Journal of Public Health Medicine, vol. 20, no. 1, pp. 5-10, 1998.

[87] S. C. Hsieh, J. N. Lai, P. C. Chen, H. J. Chen, and J. D. Wang, "Development of active safety surveillance system for traditional Chinese medicine: an empirical study in treating climacteric women," Pharmacoepidemiology and Drug Safety, vol. 15, no. 12, pp. 889-899, 2006.

[88] M. J. Martena, J. C. A. van der Wielen, L. F. J. van de Laak, E. J. M. Konings, H. N. de Groot, and I. M. C. M. Rietjens, "Enforcement of the ban on aristolochic acids in Chinese traditional herbal preparations on the Dutch market," Analytical and Bioanalytical Chemistry, vol. 389, no. 1, pp. 263-275, 2007.

[89] Y. Li, M. Tian, J. Yu, M. Shang, and S. Cai, "Studies on morphology and aristolochic acid analogue constituents of Asarum campaniflorum and a comparison with two official species of Asari Radix et Rhizoma," Journal of Natural Medicines, vol. 64, no. 4, pp. 442-451, 2010.

[90] J. Hwang, S. D. Hur, and Y. B. Seo, "Mineralogical and chemical changes in pyrite after traditional processing for use in medicines," American Journal of Chinese Medicine, vol. 32, no. 6, pp. 907-919, 2004.

[91] Y. A. Chen, J. R. Hsu, S. H. Ferng et al., "Tubulointerstitial nephritis-an under-recognized renal disease," Acta Nephrologica ROC, vol. 21, pp. 11-16, 2007. 


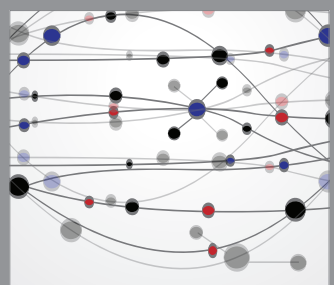

The Scientific World Journal
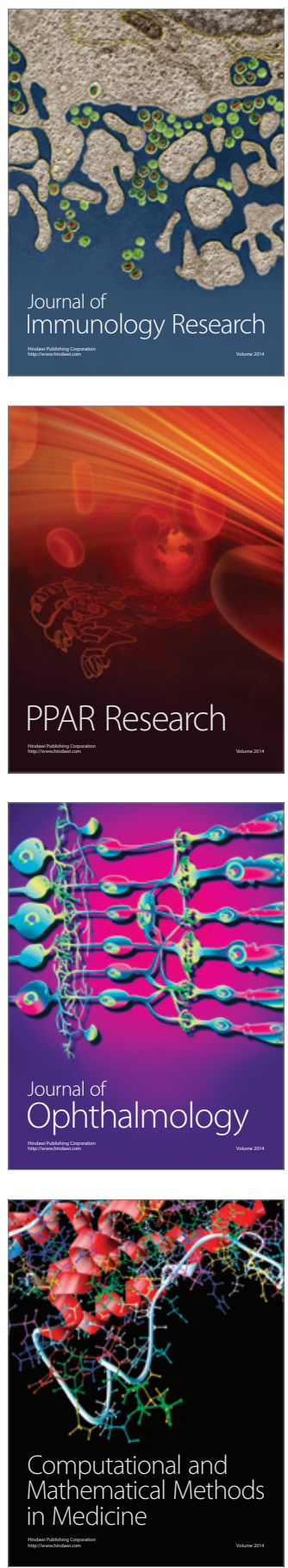

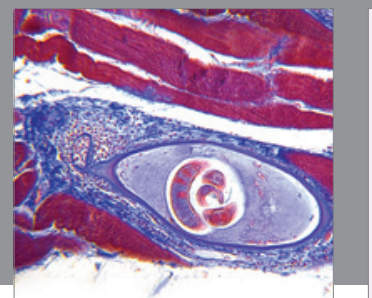

Gastroenterology

Research and Practice
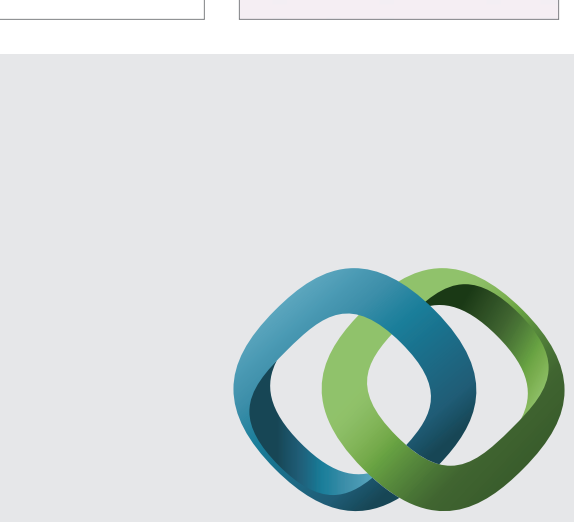

\section{Hindawi}

Submit your manuscripts at

http://www.hindawi.com
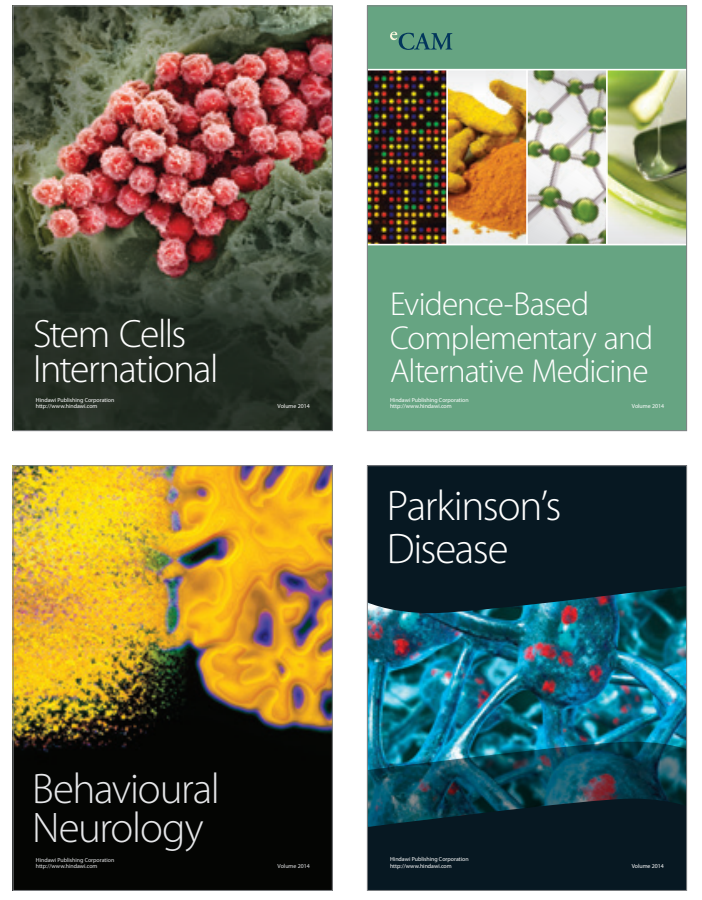
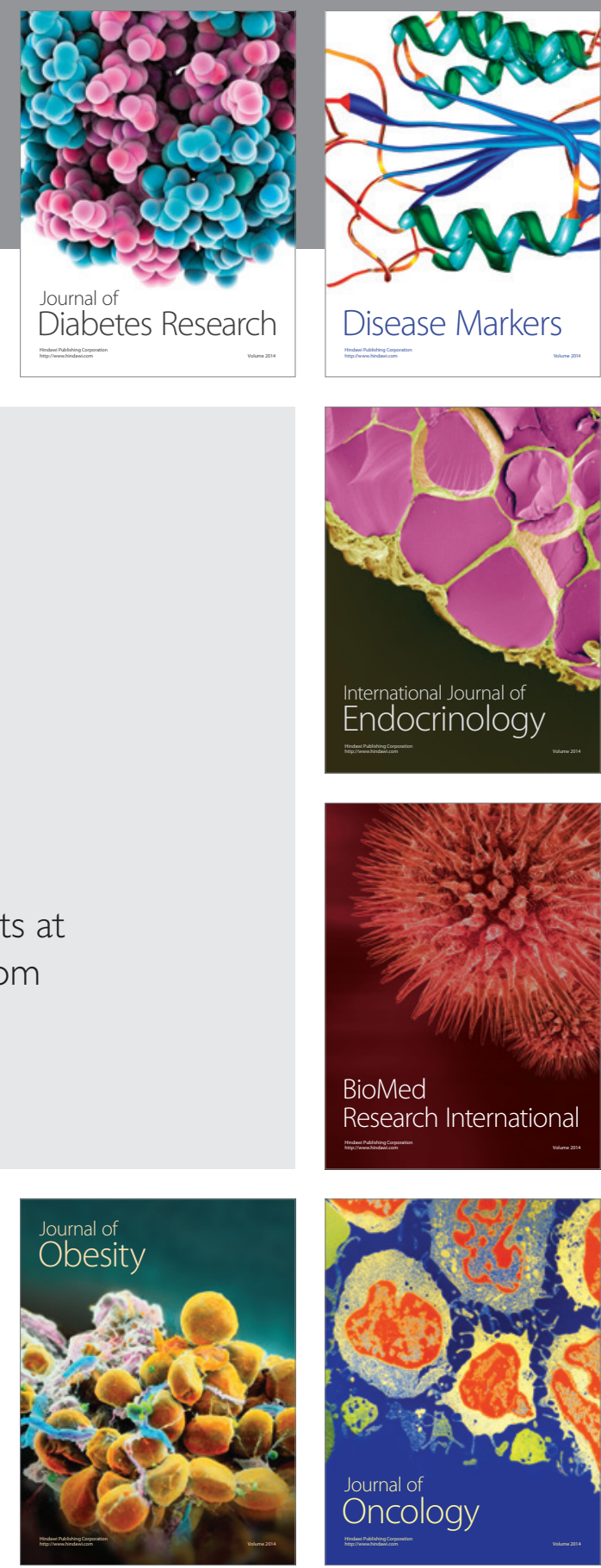

Disease Markers
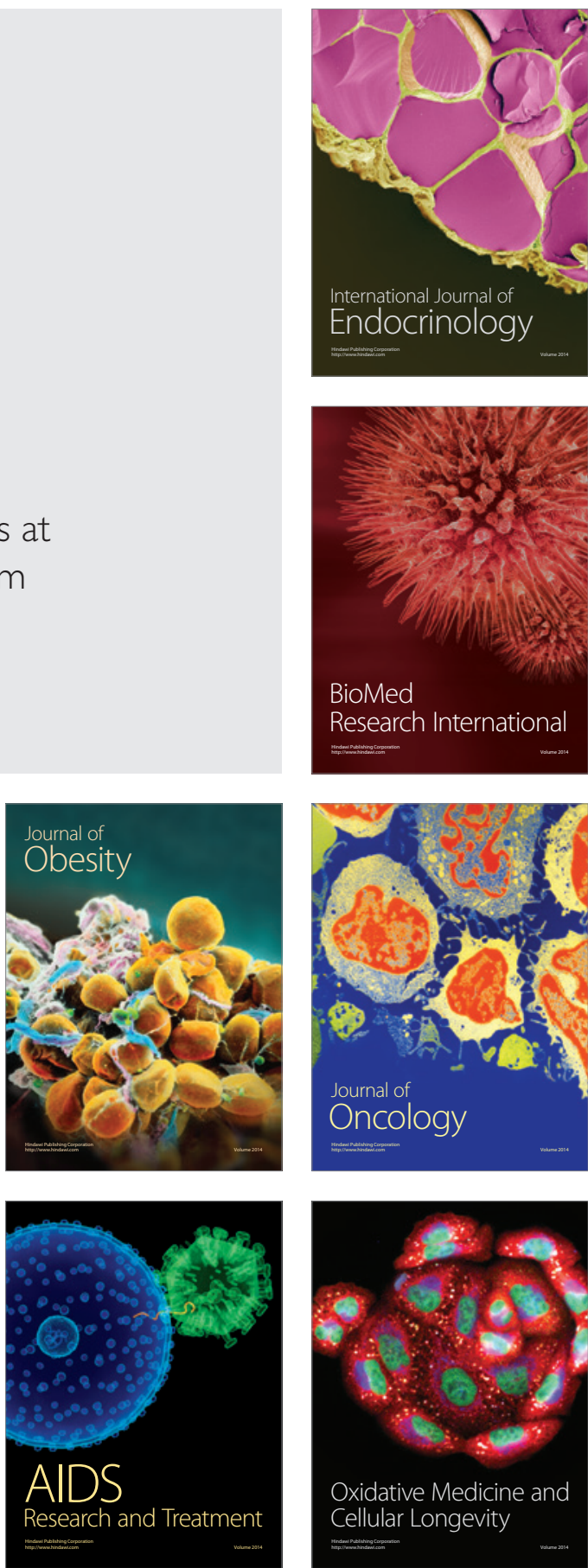